\title{
Heads in Oceanic Indirect Possession
}

\author{
Bill Palmer and Dunstan Brown
}

\author{
UNIVERSITY OF SURREY
}

\begin{abstract}
In many Oceanic languages the "indirect" possessive construction, which is typically associated with alienable possession, uses special forms to host person and number agreement indexing the possessor. This can be contrasted with the "direct" possessive construction, typically associated with inalienable possession, where a lexical possessum noun itself carries possessor-indexing agreement. The host forms used in the indirect construction are often referred to as "classifiers." We argue that this term should not be applied to indirect possession marking in many Oceanic languages, and present evidence to show that indirect possessor-indexing hosts in such languages do not have the properties typically associated with classifiers. In contrast with this, we further argue that these indirect possessor-indexing hosts should be treated as the syntactic head of the noun phrase in which they occur, thereby allowing treatment of the syntax of NPs with indirect possession that is consistent with those with direct marking. In both instances, the person and number indexing morphology simply attaches to the syntactic head.
\end{abstract}

1. DIRECT AND INDIRECT POSSESSOR-INDEXING. ${ }^{1}$ Most Oceanic languages encode possession in two distinct ways, typically associated with inalienable and alienable possessive relations, respectively. One, termed "direct possession" in the Oceanist literature, involves direct possessor agreement suffixation of the possessum noun, shown for Kokota (Meso-Melanesian) (Palmer n.d., 2002, to appear) in (I).

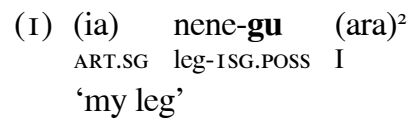

(Kokota)

I. The support of the United Kingdom Arts and Humanities Research Council under grant B/RG/ AN4375/APNi9365 is gratefully acknowledged. The authors collaborated equally on the theoretical investigation of an original insight by Palmer. A version of this article was presented at the thirteenth annual meeting of the Austronesian Formal Linguistics Association, National Tsing Hua University, Hsinchu, Taiwan, March 24-26, 2006. We are grateful to Mark Donohue, Edward Keenan, Norvin Richards, and Malcolm Ross for questions and comments on the work presented there. We also thank John Lynch and Byron Bender for comments on a draft version of the paper, Greville Corbett for discussions at various stages, and Paul Geraghty for comments and additional Fijian data. All errors and omissions are, of course, our responsibility.

2. We follow the Leipzig glossing rules. Where they give no standard abbreviation, we use the following: DRINK, 'drink' possessor-indexing host; EMPH, emphatic; FOOD, 'food' possessorindexing host; GENPOSS, general possessor-indexing host; POSs, invariant possessor-indexing host in languages with only one; RL, realis modality; CNSM, 'consumed' possessor-indexing host; SBD, subordinator. 
The other, termed "indirect possession," involves agreement marking of one of a small closed set of forms that accompany the possessum noun. Many Oceanic languages have exactly two indirect host forms in this closed set. In these languages, the forms always function to distinguish items that have been, are being, or will be consumed, as in (2b), from a residual category of general possessions, as in (2a). This is the case in Kokota:
(2) a. (ia) no-gu suga (ara) ART.SG GENPOSS-ISG.POSS house I 'my house'
b. (ia) ye-gu kaku (ara) ART.SG CNSM-I.SG.POSS banana I 'my banana (to eat)'

(Kokota)

(Kokota)

In some Oceanic languages, only one indirect possessor-indexing host occurs, as in Yapese (Jensen I977; Ballantyne, Manna, and Kenrad 2002):

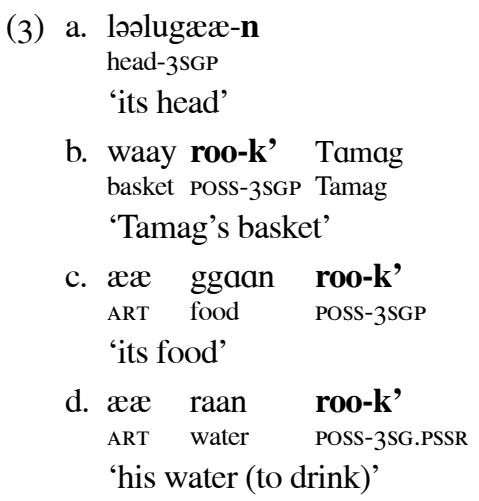

(Yapese)

(Yapese)

(Yapese)

In others, three occur, with the consumable category being further differentiated into a category of items that have been, are being, or will be eaten (4b) and a category of items that have been, are being, or will be drunk (4c), as well as a general default category (4d), as in Standard Fijian (Geraghty I983; Schütz I985):

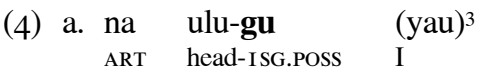

$$
\begin{aligned}
& \text { 'my head' } \\
& \text { b. na ke-gu man }{ }^{n} \text { rai } \\
& \text { ART FOOD-ISG.POSS bread } \\
& \text { 'my bread' } \\
& \text { c. na me-gu yagona } \\
& \text { ART DRINK-ISG.POSS kava } \\
& \text { 'my kava' } \\
& \text { d. na no-gu } \quad \text { ßale } \\
& \text { ART GENPOSS-ISG.POSS house } \\
& \text { 'my house' }
\end{aligned}
$$$$
\text { (Standard Fijian) }
$$$$
\text { (Standard Fijian) }
$$

(Standard Fijian)

3. Voiced plosives in Standard Fijian are prenasalized, but as this is a subphonemic feature, it is not represented in transcription here, except with the prenasalized rhotic, where it is phonemically distinctive. 
Many Oceanic languages have exactly one, two, three, or four such host forms (Ross 2005), although larger numbers of hosts occur in various languages.

The issue under investigation in this article is the syntactic status of these indirect possessor-indexing host forms, and the structure of the NPs in which they occur. This issue will be investigated with special reference to Kokota.

2. TRADITIONAL ANALYSIS. It has traditionally been assumed that these possessor-indexing hosts are classifiers, syntactically functioning as dependents modifying a head noun located to their right.

This analysis is somewhat problematic, as most Oceanic languages, including Kokota, are left-headed, with NP modifiers following the head noun, not preceding it:

(5) a. (ira) mane tove $=$ ro

ART.PL man old=DEM

'those old men'

(Kokota)

b. (ira) mane dou=ro

ART.PL man be.big=DEM

'those big men'

(Kokota)

c. (ira) mane vave $=$ ro

ART.PL man in.law=DEM

'those men [who are] in-laws'

(Kokota)

Lexical post-head modifiers in Kokota may be one of a very small closed class of adjectives, as in (5a), a verb (5b), or a noun (5c), and may be followed by a demonstrative. The NPs in (5) are left-headed, within left-headed DPs with an optional specifier (here ira, a plural article).

The possibility that indirect possessor-indexing hosts in languages like Kokota are not classifiers that function syntactically as prehead modifiers, as traditionally assumed, but instead are the syntactic head of the NP in which they occur, has never been properly tested. We test this hypothesis by examining these hosts in Kokota in the light of criteria for headhood, and for classifier status.

\section{INDIRECT POSSESSOR-INDEXING HOSTS AS CLASSIFIERS}

\subsection{POSSESSOR-INDEXING HOSTS AS ENCODERS OF RELATION-}

SHIPS. Lichtenberk (I983) argues that forms in Oceanic such as those under investigation here are relational classifiers. His view is that they do not classify the nouns with which they occur, but instead classify the relation that holds between the possessum and possessor. We agree with Lichtenberk's argument that these hosts mark the relation that holds between possessor and possessum, but argue that the notion classifier here is particularly problematic.

Kokota behaves in a way that accords with Lichtenberk's (I983) claim that indirect possessor-indexing forms mark the actual relationship between possessor and possessum, rather than classes or types of nouns or their referents. A single $\mathrm{N}$ in Kokota may be possessor-indexed using either the "consumed" or general indirect host, or indeed 
using direct possessor-indexing, depending on the semantic relationship between its referent and the referent of the possessor NP. In (6a) the leg is in a part-whole relationship with its possessor and is directly indexed. In (6b) it is eaten, perhaps the leg of a chicken or pig that the possessor intends to eat; while in (6c) it is a leg intended for some other purpose, such as the leg of a dismantled table intended to be used for firewood or as timber.

(6) a. nene-gu

leg-ISG.POSS

'my leg (of my body)'

(Kokota)

b. ye-gu nene

CNSM-ISG.POSS leg

'my leg (to eat)'

(Kokota)

c. no-gu nene

GENPOSS-ISG.POSS leg

'my leg (for some other purpose)'

(Kokota)

So, the possessor-indexing host actually marks the nature of the relationship between the possessed noun and the possessor.

Even an independent physical entity may be possessed variably. In (7a) the bird is referred to as an ordinary possession such as a pet. In (7b) it is thought of as being intended for eating. This may refer to bird meat, or to a living bird that is intended to be killed and eaten. In $(7 \mathrm{c})$ the bird is thought of as being in an inalienable relation to the place to which it is endemic.

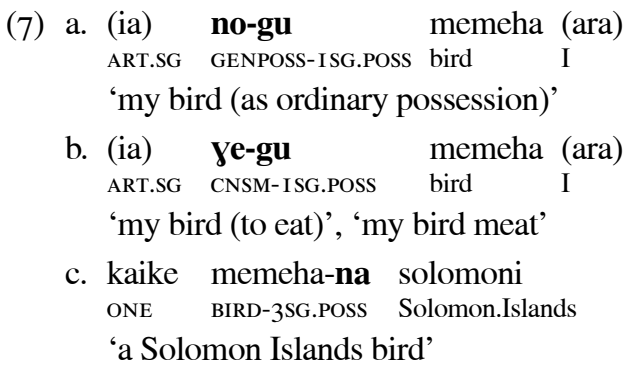

(Kokota)

(Kokota)

However, Lichtenberk (I983) does not take his argument to its logical conclusion. If these forms refer to relations that hold between entities, and do not classify nouns or their referents, they do not conform to the standard notion of a classifier as classifying nouns. As possessor-indexing hosts in languages such as Kokota do not classify either nouns or their referents, either they are therefore not classifiers, or the term classifier must be redefined more broadly. If the term "classifier" is redefined, then some other way needs to be found to distinguish between the classification of nouns or their referents, and relations that hold between participants. This distinction would then place possessor-indexing hosts outside the definition of the narrow group of forms that classify nouns or nominal referents, a group that corresponds to the standard notion of classifier. Either way, Oceanic possessor-indexing hosts in languages such as Kokota do not satisfy the functional criteria for the standard notion of classifier. 
Grinevald (2000:66) claims that "genitive classifiers," including those in Oceanic, are "usually bound to the mark of the possessor, while semantically classifying the possessed." This is not, in fact, the case in Oceanic. Indirect possessor-indexing hosts have a tighter syntactic relationship with the possessum noun than the possessor NP, and classify the relationship between the possessor and a possessum, not a possessum noun or its referent.

Because they refer to and classify the relation between two participants, rather than the participants themselves, they are the functionally most important constituent in the phrase. This means that the possessor-indexing host is a "semantic head" (Zwicky I985:4): the relationship itself between the possessor and possessum is the most important information, and the possessum noun further specifies this. Possessor-indexing hosts are therefore functionally consistent with being head.

The fact that these possessor-indexing hosts mark the relationship between possessor and possessum means that there are strong parallels, as far as this dimension is concerned, with Wilkins's (2000) analysis of classifier constructions in Arrernte. Wilkins (2000:206-8) argues that the classifier construction in that language is more accurately represented as a "generic-specific construction," in which forms traditionally described as classifiers are, in fact, generic nouns whose referents are specified in more detail by an accompanying noun. We argue that in the relevant Oceanic languages a more extreme form of this functional relationship exists. Standard Fijian, for example, has exactly three generic nouns, meaning respectively 'possessed item', 'item eaten', and 'item drunk'. Kokota has exactly two, meaning respectively 'possessed item' and 'item consumed', while Yapese has exactly one, meaning 'possessed item'.

In sum, the possessor-indexing hosts are relational in the sense of Lichtenberk (I983), but this property could also be seen as putting their status as classifiers in question.

\subsection{POSSESSOR-INDEXING HOSTS AND CLASSIFIER CRITERIA.} A number of criteria occur commonly in the literature on classifiers (e.g., Dixon I986, Grinevald 2000). Key among these are that classifiers:

- do not classify all nouns (Dixon I986:I06; Grinevald 2000:62)

- comprise an open class of a largish number of items (Dixon I986: Io6; Grinevald 2000:62)

- function primarily to individuate referents (Grinevald 2000:74-76)

- only occur in NPs that are referential (an assumption implicit in most literature on classifiers, though rarely stated explicitly).

We now demonstrate that possessor-indexing hosts in most Oceanic languages fail to conform to these criteria.

3.2.1 Exhaustive classification. In Oceanic languages like Kokota, any of the possessor-indexing hosts may occur with almost any common noun, subject to pragmatic or semantic compatibility. Grinevald (2000:66) claims that a "genitive classifier system" "selects a limited set of nouns of the language for classification: they are nouns that appear to have high cultural significance." They "select particularly essential objects of the environment to be obtained or owned to attend to one's basic survival needs" (Grinevald 
2000:78). Again, this is not true for Oceanic languages with indirect possessor-indexing hosts such as Kokota. In these languages, every common noun may be possessed, and if not participating in a direct possessive construction, when possessed must occur with an indirect possessor-indexing host, even if their referent is of absolutely no cultural significance whatsoever. Indeed, there is a tendency in Oceanic for items of high cultural significance to be directly possessor-indexing, and not employ an indirect host at all.

3.2.2 Closed-class items. Indirect possessor-indexing hosts in most Oceanic languages belong to a very small closed class, consisting in languages such as Kokota of exactly two items, in languages such as Standard Fijian exactly three, and in languages such as Yapese just a single item.

3.2.3 Individuation. Individuation is often seen as a key property of classifiers (see Grinevald 2000:74-76 and references there). The idea is that the nouns that undergo classification are concept nouns, and that individuation is a process of making these nouns more concrete, typically in relation to quantification. Grinevald (2000:75) illustrates this using English examples:
Mass
vs.
Count
a lot of furniture
many pieces of furniture

While the details differ cross-linguistically, a key point is that the concept noun (such as furniture) needs a classifier in order to be individuated in some way. This should primarily explain why there are gaps in noun classification, as there will be nouns that do not require individuation through classifiers.

It is clear that the Oceanic possessor-indexing hosts under discussion do not fit this view of classifiers. Because they describe a relation between possessor and possessum, the classification does not involve a partition of nouns into "concept" and "nonconcept," and the system, while allowing for nouns to enter into multiple classification relationships, has very few gaps.

3.2.4 Nonreferentiality. In many Oceanic languages, possessor-indexing hosts may be used nonreferentially, occurring without a more specific referent than 'possessed item' or 'item consumed', and so on, and without a specific referent identifiable from the discourse or discourse context. In (9), for example, the referents of the highlighted possessor-indexing hosts are generic, referring only to possessions and food, without any more specific referent intended by the speaker, and are newly introduced into the discourse, lacking antecedents or referents in the discourse context.

(9) teo boka mai au-na yai ade

be.not be.able come exist-DEM IPL.EXCL here

'We can't come and live here,

$\begin{array}{llll}\text { nafu-na } & \text { n-a-Ye } & \text { zaho } & \text { koko-di } \\ \text { base-3SG.POSS } & \text { RL-I.SUBJ=PRS go.away } & \text { leave=3PL.OBJ } \\ \text { because we would leave behind } & & \\ \text { ira ye-mai } \quad \text { no-mai } & \text { eu, huhurani } \\ \text { ART.PL CNSM-IEXC.POSS } & \text { GENPOSS-IEXC.POSS } & \text { EMPH } & \text { Huhurangi } \\ \text { our food and our things, at Huhurangi. } & \end{array}$




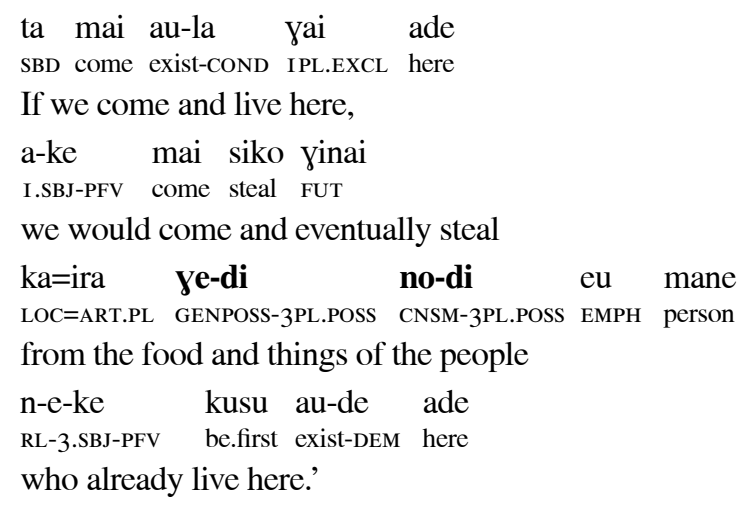

(Kokota)

If possessor-indexing hosts can be nonreferential, as they are in (9), this precludes the possibility that they must be specific.

3.2.5 Summary. Possessor-indexing hosts in Oceanic languages such as Kokota fail to have a number of important properties typically associated with classifiers. The traditional assumption that these items are classifiers implicitly precluded their analysis as NP head, classifiers being defined by Dixon (I986:I08) in part as occurring "in syntactic construction with the head noun." The failure of possessor-indexing hosts to meet the criteria for classifier status opens the possibility that they are the head of the constructions in which they occur.

4. POSSESSOR-INDEXING HOSTS AS HEADS. We argue that these indirect possessor-indexing hosts meet key criteria for headhood, specifically: obligatoriness, category determinance, distributional equivalence, and morphosyntactic locushood (Zwicky I985, I993).

4.1 OBLIGATORINESS. In Oceanic languages such as Kokota, indirect possessor-indexing hosts are obligatory, while the adjacent fully specified possessum noun is optional, as a comparison of (IOa) and (IOb) shows.

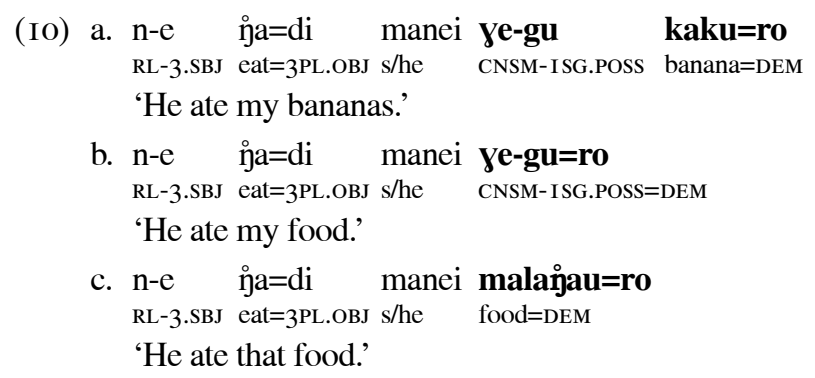

(Kokota)

(Kokota)

(Kokota)

In discussing obligatoriness and heads, Zwicky (I993:297) points out that while heads are the required element in a construction, it is possible to treat heads as elided. For example, Zwicky gives the Verb Phrase turkey in I ate chicken, and Kim turkey as grammatical but elliptical and missing the verb head ate. The crucial point is that the interpretation of 
the phrase is dependent on context and the ability to recover a missing head. This is why ate in Zwicky's example is elided, rather than simply absent from the clause.

However, this does not apply to examples such as (IOb). Instead, the NP can be fully interpreted without recourse to a recoverable nominal referent. The lack of a referential noun in (IOb) as opposed to (IOa) is connected with the possibility that the referent need not be specific. This was demonstrated in (9), where the possessor-indexing hosts are nonreferential, requiring that they be nonspecific.

To summarize, it cannot be claimed that in examples such as (Iob) the object NP is in fact the same as that in (IOa), with the nominal head elided because it is recoverable from the discourse, by having an anaphoric referent, or being present at the time of utterance. Section 3.2 demonstrated that possessor-indexing hosts may be nonreferential. The data in (9) showed NPs with possessor-indexing hosts that are nonreferential and therefore cannot require recourse to an elided referential noun for interpretation.

4.2 CATEGORY DETERMINANCE. Because indirect possessor-indexing hosts are the only obligatory element in phrases in which they occur, they must logically therefore be the category determinants for those phrases.

4.3 DISTRIBUTIONAL EQUIVALENCE. Indirect possessor-indexed hosts are distributionally equivalent to clearly lexical nouns in languages such as Kokota. We demonstrate this using a number of constructions.

4.3.1 Distribution as sole form in object NP. In example (IOb) the possessorindexing host has a distribution comparable with that of the lexical noun in (IOc). That is, they both occur as the sole overt form in an object NP.

4.3.2 Collocation with specifying bare $N$. In (IOa) the host occurs immediately followed by a bare $\mathrm{N}$ that specifies more precisely the nature of the referent, directly paralleling the modification of clearly lexical nouns as in $(5 \mathrm{c})$, where the head noun is modified by a following single bare noun specifying in more detail the nature of the head's referent.

4.3.3 Participation in incorporation. Possessor-indexing hosts in Kokota participate in incorporation in a way that parallels that of clearly lexical nouns.

In Kokota incorporation, the undergoer $\mathrm{N}$ occurs immediately adjacent to an intransitive form of a potentially transitive verb. In ( I Ia) there is no incorporation. This can be seen by the presence of object-indexing on the verb, and the word order VSO. Kokota has a pragmatically unmarked word order VSO. The order VOS also occurs when the subject is in a clause-final focus position. However, in this construction overt focus marking of the $\mathrm{S}$ is obligatory, as ( $\mathrm{I} \mathrm{Ib}$ ) illustrates.

(I I) a. n-a Đo=di ara kaku ide
RL-I.SBJ eat=3PL.OBJ I banana

(Kokota)

(Kokota) 
In (I2), however, the undergoer/object noun is incorporated. This can be seen by the lack of object-indexing on the verb, and the presence of the undergoer $\mathrm{N}$ between the verb root and the subject NP in a clause lacking focus marking of the subject required in a VOS clause.

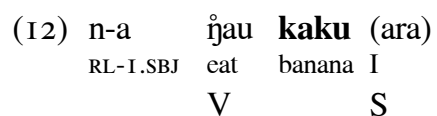

'I'm eating bananas.'

(Kokota)

Unusually, Kokota allows incorporation of nouns referring to possessed entities:

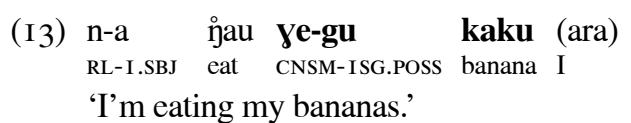

'I'm eating my bananas.'

(Kokota)

Indirect possessor-indexed forms behave in the same way as clearly lexical nouns in that they may be incorporated without a specifying nominal:
(I4) n-a Đou ye-gu (ara)
RL-I.SBJ eat CNSM-ISG.POSS I
'I'm eating my food.'

(Kokota)

The clause in (I4) may be compared with (I5):

$\begin{array}{llll}\text { (I5) } & \text { n-a } & \text { ỷau malạ̊au (ara) } \\ \text { RL-I.SBJ } & \text { eat food } & \text { I }\end{array}$

'I'm eating food.'

(Kokota)

This contrast directly parallels that seen with the unincorporated NPs in (IO), with (I3), (I4), and (I5) paralleling (IOa), (IOb), and (IOc), respectively. As in (IO), the key semantic distinction here is between (I2) and (I3), where we claim the NPs have different structures, rather than between (I4) and (I5), where we claim that the NPs have the same structures.

4.4 MORPHOSYNTACTIC LOCUS. By hosting the possessor-indexing suffixes, these hosts are the morphosyntactic locus of the construct in which they occur, as they mark the relation between that construct and the external possessor.

Even given the possibility that the head need not always be the morphosyntactic locus cross-linguistically, we should bear in mind that viewing the possessor-indexing hosts as nonheads complicates the syntax of possession marking in the relevant languages. On the one hand, we would need to make reference to the right edge of the phrase to place the possessor-indexing in the direct construction in (I6).

(I6) [(ia)[nene-gu]]

On the other hand, we could not easily do this for the indirect possessor-indexing in (I7).

(I7) [(ia)[no-gu suga $]$

By interpreting the possessor-indexing host as head, the morphosyntax of possessorindexing can be seen to be consistent in (I6) and (I7). The indexing morphology simply attaches to the head. Thus treating the possessor-indexing hosts as heads is consistent with their being morphosyntactic loci, and it makes it simple to state where possessor-indexing is located in the phrase. 
5. HOSTS AS HEADS ELSEWHERE IN OCEANIC. The claims made above are illustrated with data from Kokota. However, we are claiming that Kokota is not atypical in this regard. The syntactic head status demonstrated above for Kokota indirect possessor-indexing hosts is widespread throughout Oceanic, although we are not claiming that it is necessarily the case in every Oceanic language. The omission of the lexical possessum noun and the potential nonreferentiality of the possessor-indexing host are not mentioned in most Oceanic descriptions, but are present in the data in languages distributed as widely across Oceanic as Standard Fijian (Central Pacific subgroup) shown in (I8a), Lewo (Southern Oceanic subgroup) (Early I994) in (I8b), and Kilivila (Papuan Tip) (Senft I986) in (I8c):

(I8) a. da dui kaut-a mai [na ke-na kei na me-na] IINCLS each bring-TR hither ART FOOD-3SGP and ART DRINK-3SGP 'Each of us should bring our own food and drink.' (Standard Fijian)

b. me-ka-n [ka-mim] lala IEXCLS-eat-TR FOOD-IEXCLP DISTR

'We each ate our own food.'

$$
\begin{array}{llll}
\text { c. } \text { i-kumli ina-la } & \text { [ka-la } & \text { (kaula)] i-vinaku } \\
\text { 3SGS-make.earth.oven mother-3SGP } & \text { CNSM-3SGP food } & \text { 3SGS-finish }
\end{array}
$$

'His mother has finished earth oven cooking his food.' (Kilivila)

Senft (I986:48) explicitly presents the data in (I8c) with and without the noun kaula 'food', with no difference in meaning, as an example of the omissability of nouns when accompanied by "possessive pronouns" in Kilivila, although he draws no syntactic conclusions from this fact.

We do not claim an exhaustive survey of this aspect of the grammar across Oceanic. However, we do claim that the indirect possessor-indexing hosts in Kokota are demonstrably the syntactic head of the NP in which they occur, and that there is evidence that they have the same syntactic status in a range of other languages from across Oceanic.

6. CONCLUSION. We have argued that possessor-indexing hosts in at least some Oceanic languages function as the syntactic head of the phrase in which they occur. This allows a simpler, unified analysis of the morphology and syntax of NPs in the relevant languages. For example, in Kokota:

- NPs with and without indirect possessor-indexing hosts are left-headed;

- a single post-head position exists in which a bare $\mathrm{N}$ may occur specifying in detail the nature of the head-in NPs without possessor-indexing this may specify in more detail the nature of the referent of the head, as in (5c), while in NPs displaying possessor-indexing, it specifies in more detail the nature of the possessum, as in (2);

- possessor-indexing morphology attaches to the head of any NP expressing a possessed entity, as in (I6) and (I7).

We argue that these possessor-indexing hosts are not classifiers that modify a possessum noun, as typically claimed, but are directly possessed generic nouns, and that the possessum noun fills an NP posthead modifier position, specifying the nature of the possessed entity. 
This challenges traditional assumptions about the morphosyntactic behavior and function of such forms in Oceanic. We also draw attention to aspects of the typology of classifiers that have not been clearly explicated in the existing literature, specifically a lack of clear distinction between forms that encode information about a nominal or its referent, and those that refer to a relationship that holds between entities, and the extent to which the latter category may be regarded as classifiers at all.

\section{REFERENCES}

Ballantyne, Keira Gebbie, Sherri Manna, and Angela Y. Kenrad. 2002. Colonia corpus of spoken Yapese. Honolulu: University of Hawaii. www2.hawaii.edu/ $\%$ 7Eballanty/corpusintro.html\#Colonia_Corpus_of_Spoken_Yapese

Dixon, R. M. W. I986. Noun classes and nominal classification in typological perspective. In Noun classes and categorization, ed. by Colette Grinevald Craig, I05-I 2. Amsterdam: John Benjamins.

Early, Robert. I994. A grammar of Lewo, Vanuatu. PhD diss., Australian National University.

Geraghty, Paul. I983. The history of the Fijian languages. Honolulu: University of Hawai' $i$ Press.

Grinevald, Colette. 2000. A morphosyntactic typology of classifiers. In Systems of nominal classification, ed. by Gunter Senft, 50-92. Cambridge: Cambridge University Press.

Groves, Terab'ata R., Gordon W. Groves, and Roderick Jacobs. I985. Kiribati: An outline description. Canberra: Pacific Linguistics.

Jensen, John Thayer. I977. Yapese reference grammar. Honolulu: University of Hawai ' $\mathrm{i}$ Press.

Lichtenberk, Frantisek. I983. Relational classifiers. Lingua 60: I47-76.

Palmer, Bill. 2002. Kokota. In The Oceanic Languages, ed. by John Lynch, Malcolm Ross, and Terry Crowley, 498-524. London: Curzon.

. n.d. Kokota field notes.

. To appear. Kokota grammar. Honolulu: University of Hawai 'i Press.

Ross, Malcolm. 2005. The typology and history of possession in Oceanic: A construction that should never have existed. Seminar, Oxford University.

Schütz, Albert J. 1985. The Fijian language. Honolulu: University of Hawai 'i Press.

Senft, Gunter. I986. Kilivila: The language of the Trobriand Islanders. Berlin: Mouton de Gruyter.

Wilkins, David P. 200o. Ants, ancestors and medicine: A semantic and pragmatic account of classifier constructions in Arrente (Central Australia). In Systems of nominal classification, ed. by Gunter Senft, I47-2 I6. Cambridge: Cambridge University Press.

Zwicky, Arnold M. I985. Heads. Linguistics 2 I: I-29.

- I993. Heads, bases and functors. In Heads in grammatical theory, ed. by Greville G. Corbett, Norman M. Fraser, and Scott McGlashan, 292-3I5. Cambridge: Cambridge University Press.

Surrey Morphology Group

Department of Culture, Media and Communication

University of Surrey

Guildford, Surrey, GU2 $7 \mathrm{XH}$, UK

bill.palmer@surrey.ac.uk, d.brown@surrey.ac.uk 